\title{
Hyper-Reactive Human Ventral Tegmental Area and Aberrant Mesocorticolimbic Connectivity in Overgeneralization of Fear in Generalized Anxiety Disorder
}

\author{
Jiook Cha (차지욱), ${ }^{1,2}$ Joshua M. Carlson, ${ }^{3,4}$ Daniel J. DeDora, ${ }^{3}$ Tsafrir Greenberg, ${ }^{5}$ Greg H. Proudfit, ${ }^{5}$ \\ and Lilianne R. Mujica-Parodi ${ }^{1,3,6}$ \\ ${ }^{1}$ Program in Neuroscience, Stony Brook University, Stony Brook, New York 11794, ${ }^{2}$ Department of Psychiatry, Columbia University College of Physicians \\ and Surgeons and the New York State Psychiatric Institute, New York, New York 10032, ${ }^{3}$ Department of Biomedical Engineering, Stony Brook University \\ School of Medicine, Stony Brook, New York 11794, ${ }^{4}$ Department of Psychology, Northern Michigan University, Marquette, Michigan 49855, ${ }^{5}$ Department of \\ Psychology, Stony Brook University, Stony Brook, New York 11794, and ${ }^{6}$ Department of Radiology, Athinoula A. Martinos Center for Biomedical Imaging, \\ Massachusetts General Hospital, Charlestown, Massachusetts 02129
}

The ventral tegmental area (VTA) has been primarily implicated in reward-motivated behavior. Recently, aberrant dopaminergic VTA signaling has also been implicated in anxiety-like behaviors in animal models. These findings, however, have yet to be extended to anxiety in humans. Here we hypothesized that clinical anxiety is linked to dysfunction of the mesocorticolimbic circuit during threat processing in humans; specifically, excessive or dysregulated activity of the mesocorticolimbic aversion circuit may be etiologically related to errors in distinguishing cues of threat versus safety, also known as "overgeneralization of fear." To test this, we recruited 32 females with generalized anxiety disorder and 25 age-matched healthy control females. We measured brain activity using fMRI while participants underwent a fear generalization task consisting of pseudo-randomly presented rectangles with systematically varying widths. A mid-sized rectangle served as a conditioned stimulus (CS; $50 \%$ electric shock probability) and rectangles with widths of CS $\pm 20 \%, \pm 40 \%$, and $\pm 60 \%$ served as generalization stimuli (GS; never paired with electric shock). Healthy controls showed VTA reactivity proportional to the cue's perceptual similarity to CS (threat). In contrast, patients with generalized anxiety disorder showed heightened and less discriminating VTA reactivity to GS, a feature that was positively correlated with trait anxiety, as well as increased mesocortical and decreased mesohippocampal coupling. Our results suggest that the human VTA and the mesocorticolimbic system play a crucial role in threat processing, and that abnormalities in this system are implicated in maladaptive threat processing in clinical anxiety.

Key words: anxiety disorder; dopaminergic aversion system; fear generalization; human fear conditioning; mesocorticolimbic system; ventral tegmental area

\section{Introduction}

The midbrain ventral tegmental area (VTA) is a central part of the mesocorticolimbic dopaminergic system, which plays a pivotal role in motivation (Berridge and Robinson, 1998; Schultz, 2002). Previous studies demonstrate that this system may be one of the primary target sites of stress-induced disturbance. Early research in rodent models revealed that stress exposure activates dopami-

\footnotetext{
Received Nov. 18, 2013; revised March 17, 2014; accepted March 21, 2014.

Author contributions: T.G., G.H.P., and L.R.M.-P. designed research; J.C. and T.G. performed research; J.C. analyzed data; J.C., J.M.C., D.D., G.H.P., and L.R.M.-P. wrote the paper.

We thank L. Role for insightful discussions. This research was supported by the Office of Naval Research (\#N001404-1-005, LRMP) and the National Science Foundation (\#0954643, LRMP). The authors declare no competing financial interests.

The authors declare no competing financial interests.

Correspondence should be addressed to Dr. Lilianne R. Mujica-Parodi, Laboratory for Computational Neurodiagnostics, Department of Biomedical Engineering, Stony Brook, NY 11794-5281. E-mail: lilianne.strey@stonybrook.edu.

DOI:10.1523/JNEUROSCI.4868-13.2014

Copyright $\odot 2014$ the authors $\quad 0270-6474 / 14 / 345855-06 \$ 15.00 / 0$
}

nergic innervations to the prefrontal cortex (PFC) (Thierry et al., 1976; Deutch and Roth, 1990). More recent studies demonstrate that chronic stress (e.g., social defeat) results in increased VTA dopamine transmission (Anstrom et al., 2009), excessive glucocorticoid signaling in the mesocortical dopamine system (Barik et al., 2013), and epigenetic control of this system (Niwa et al., 2013). Although previous research has linked an abnormal dopamine system to depression and addiction (Willner, 1983; Zacharko and Anisman, 1991; Cabib and Puglisi-Allegra, 1996), little is known about its relationship with anxiety in humans.

Recent studies suggest that a distinct part of the mesocorticolimbic circuit plays a crucial role in negative motivation or aversion (Matsumoto and Hikosaka, 2009; Bromberg-Martin et al., 2010; Zweifel et al., 2011; Cohen et al., 2012). The VTA receives glutamatergic inputs from the lateral habenula and projects dopaminergic innervation to the medial PFC (mPFC) in rodent models (Lammel et al., 2012; Stamatakis and Stuber, 2012). The hippocampus partially controls VTA dopaminergic neuronal activity, forming the VTA-hippocampal loop 
that is crucial in motivation and memory (Lisman and Grace, 2005; Shohamy and Wagner, 2008). Therefore, normal VTA aversion signaling may depend on interconnections with the mesocorticolimbic system.

Discrimination of threat and safety is an essential aspect of aversion processing for adaptive behavior. Deficits in this process lead to an overgeneralization of conditioned fear (Kheirbek et al., 2012; Greenberg et al., 2013b; Lissek et al., 2013b); indeed, recent human studies suggest that fear overgeneralization is an important pathogenic marker of anxiety disorders, including panic disorder (Lissek et al., 2010) and generalized anxiety disorder (GAD) (Greenberg et al., 2013a; Lissek et al., 2013a). Therefore, given the crucial role of the mesocorticolimbic dopamine system in negative motivation and the impact of stress on this system, it is reasonable to postulate that maladaptive aversion processing in this system is related to the overgeneralization of conditioned fear in clinical anxiety. To the best of the authors' knowledge, no human studies have previously tested this possibility.

The aim of this study was thus to test whether individuals with clinical anxiety manifest abnormal mesocorticolimbic reactivity during threat processing (i.e., fear generalization). We hypothesized that clinical anxiety is associated with excessive VTA aversion signaling. To this end, we tested individuals with GAD and healthy control participants with a fear generalization task (Greenberg et al., 2013a, b; Cha et al., 2014), which involves the presentation of a conditioned stimulus (CS; a mid-sized rectangle paired with electric shock) or generalization stimuli (GS) varying in perceptual similarity to CS systematically while collecting functional MRI.

\section{Materials and Methods}

MR data from the same participants have been used in a previous report, which provides detailed information on the participants, the study design, and the MRI data acquisition parameters (Greenberg et al., 2013b).

Participants. Fifty-seven participants from the community around Stony Brook, New York volunteered (all females; age, mean \pm SD, $22.3 \pm$ 4.5 years). Psychiatric diagnoses were based on the Structured Clinical Interview for DSM-IV Axis I Disorders and administered by trained clinical psychologists at Stony Brook University. This procedure confirmed the diagnoses of GAD in the patient group $(n=32)$ and absence of Axis I diagnoses in the control group $(n=25)$. Of 32 patients, 17 were comorbid with major depressive disorder and 15 were diagnosed solely with GAD. All healthy controls were free of current or past psychiatric conditions. Participants were free of psychotropic medication.

Experimental procedures. After screening and consenting in accordance with a protocol approved by the Stony Brook University Institutional Review Board, participants read written instructions for the entire study. The fear generalization task was administered inside the fMRI scanner. Before the task, a voltage level was set for each participant to a level that was "uncomfortable but not painful" and was delivered to the left forearm (Constant Voltage Stimulator STM 200; Biopac Systems). Instructions for the task were then provided again verbally. Participants were told that a mid-sized rectangle (CS) indicated a 50\% probability that they would receive a subsequent electric shock but that shocks would never follow rectangles of greater or lesser size (Fig. 1). Following the instruction, we administered a conditioning phase. This included five presentations of the CS with the shock (i.e., 100\% probability) and a single presentation of each GS in a pseudo-random order with interstimulus intervals of $4-10 \mathrm{~s}$. A generalization phase immediately followed. Thus, the current study examined generalization within the context of a paradigm that combined instructed and associative threat learning.

Task. The fear generalization task consisted of the presentation of an initial fixation screen (a white cross on a black background), followed by a $2 \mathrm{~s}$ stimulus presentation. For the CS, a red rectangle was paired with a 500-ms-long electric shock with a partial reinforcement schedule of a

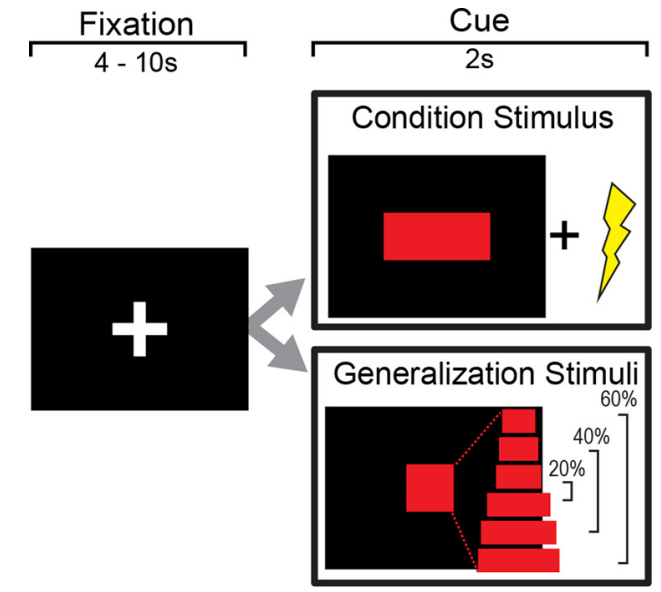

Figure 1. Fear generalization task. A period of fixation was followed by a red rectangle on a black screen (2000 ms). A midsized rectangle was paired with electric shock (500 ms duration, onset 1500 ms after cue onset) in 15 trials and unpaired in 15 trials (CS). For GS, rectangles with systematically varying widths were used (i.e., $\pm 20 \%, \pm 40 \%$, and $\pm 60 \%$ ) without paired electric shocks. Each stimulus type was presented 15 times in a pseudorandom order.

50\% delivery probability, 1500 ms after the cue onset. For GS, we used six red rectangles with systematically varying widths (i.e., $\pm 20 \%$, $\pm 40 \%$, and $\pm 60 \%$ ) without shock. Each GS was pseudo-randomly presented 15 times, and the CS was presented 30 times: 15 with shock and 15 without shock. Trials were flanked with interstimulus intervals ranging from 4 to $10 \mathrm{~s}$ with a white fixation crosshair on a black background.

MRI data acquisition. Participants were scanned with a 3T Siemens Trio scanner at the Stony Brook University Social, Cognitive, and Affective Neuroscience center. We acquired $440 \mathrm{~T} 2^{*}$-weighted echo planar images with an oblique coronal angle and TR $=2100 \mathrm{~ms}$, TE $=23 \mathrm{~ms}$, flip angle $=83^{\circ}$, matrix $=96 \times 96, \mathrm{FOV}=224 \times 224 \mathrm{~mm}$, slices $=37$, in-plane resolution $=2.33 \times 2.33 \mathrm{~mm}$ and slice thickness $=3.5 \mathrm{~mm}$. For structural scans, T1-weighted images were acquired with the following parameters: $\mathrm{TR}=1900 \mathrm{~ms}, \mathrm{TE}=2.53 \mathrm{~ms}$, flip angle $=9^{\circ}, \mathrm{FOV}=176 \times$ $250 \times 250 \mathrm{~mm}$, matrix $=176 \times 256 \times 256$, and voxel size $=1 \times 0.98 \times$ $0.98 \mathrm{~mm}$.

fMRI analysis: preprocessing. We performed preprocessing procedures in SPM 8 (http://www.fil.ion.ucl.ac.uk/spm/software/spm8/). These included slice timing correction, motion correction, spatial normalization, and spatial smoothing. For spatial smoothing, a $4 \mathrm{~mm}$ of the full-width at half maximum of the Gaussian kernel was used, as this kernel was previously reported to be effective in parametric mapping of the VTA BOLD reactivity (Ballard et al., 2011).

fMRI analysis: general linear model. For the first-level (subject level) model, we used five regressors of interest (i.e., onsets of GS $\pm 60 \%$, GS $\pm 40 \%, \mathrm{GS} \pm 20 \%, \mathrm{CS}_{\text {unpaired }}$, and $\mathrm{CS}_{\text {paired }}$ ) plus six standard motion parameters. Serial autocorrelations were modeled using a one-lag autocorrelation, and a canonical HRF was used as a basis function in model estimation. Then, a second-level (group level) random-effect analysis was performed on individuals' contrast images for each of the four conditions (i.e., each condition vs rest), excluding $\mathrm{CS}_{\text {paired }}$ The model contained three factors: subject, group, and condition. The significance of group differences in the VTA activation was corrected for multiple comparisons; after thresholding at uncorrected $p<0.005$ with voxel extent of 10, a family-wise error (FWE) small volume correction (SVC) was applied using a $4 \mathrm{~mm}$ radius sphere centered at a priori coordinates for motivation-elicited VTA activation (MNI, 3, - 17, -12) (Ballard et al., 2011).

To investigate whether VTA activity during fear generalization was associated with activity in the mesocorticolimbic aversion circuit (i.e., the $\mathrm{mPFC}$ and the hippocampus), we conducted psychophysiological interaction (PPI) analysis. A seed region in the VTA was defined from the between group contrast of all stimuli versus rest (Fig. 2). We extracted VTA time-series data within a $6 \mathrm{~mm}$ sphere centered at individual subject peaks $(p<0.05)$ within the group functional VTA mask (thresholded at 
A

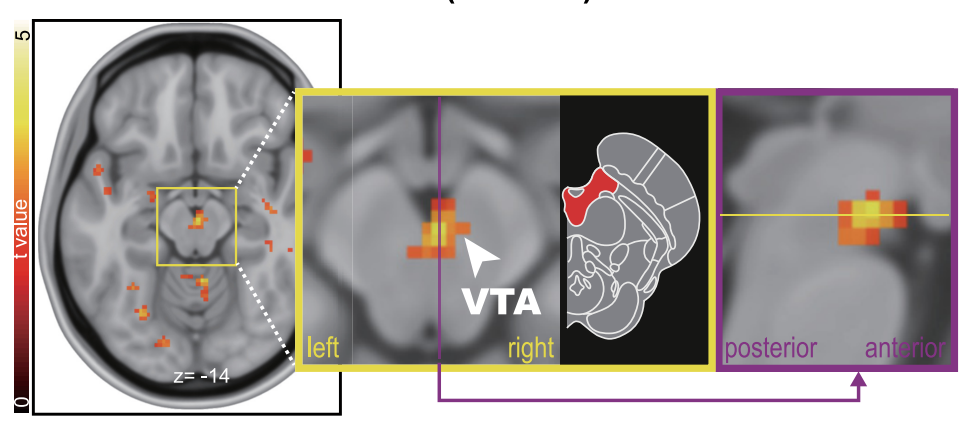

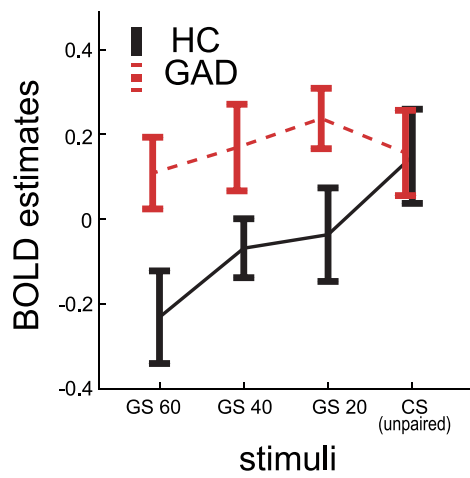

VTA functional coupling modulated by a psychological regressor:

B

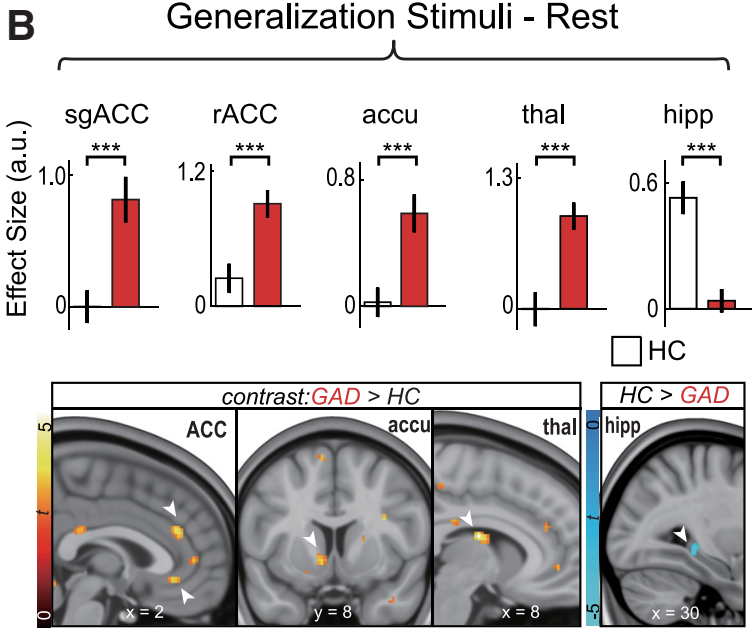

Conditioned Stimulus - Rest

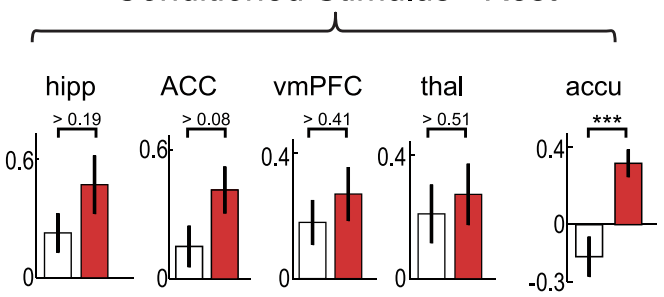

GAD

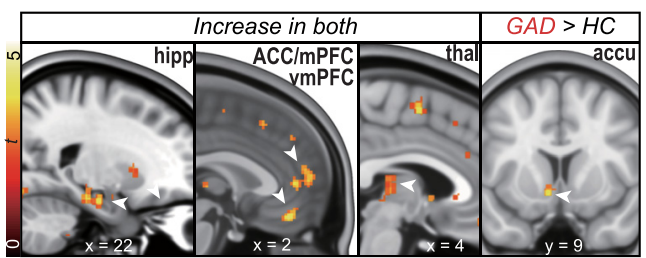

Figure 2. Heightened VTA reactivity and altered mesocorticolimbic connectivity in GAD. A, We observed heightened VTA reactivity in individuals with GAD to all stimuli, compared with healthy controls. Magnified views of the medial VTA cluster (thresholded at voxelwise $p<0.005$ and 20 continuous voxels) are shown in a coronal (yellow panel) and a sagittal view (purple panel). Diagram represents the midbrain with the VTA shown in red (modified from Naidich et al., 2009). We found greater VTA activation in GAD to GS ( $\left.p=5 \times 10^{-5}\right)$, but not CS ( $p>0.48$; one-tailed $t$ test). $B$, We performed psychophysiological-interaction analyses to examine the effects of a psychological modulator (i.e., either "GS-Rest" or "CS-Rest") on VTA connectivity. The "GS-Rest" contrast increased VTA connectivity with the subgenual and rostral ACC, accumbens, and thalamus in patients, but not in controls, whereas this contrast increased VTA-hippocampus connectivity in controls, but not in patients. The "CS-Rest" contrast, on the other hand, significantly increased VTA connectivity with the hippocampus, ACC, vmPFC, and thalamus in both groups, with an exception of connectivity with the accumbens, which was significant only in GAD patients. These results were significant at ROI-corrected $p<0.005$. Mean differences of selected voxels were examined by Mann-Whitney U test (significances denoted in the bar graphs). Accu, Accumbens; hipp, hippocampus; rACC, rostral ACC; sgACC, subgenual ACC; thal, thalamus. ${ }^{* * *} p<0.001$.

corrected $p<0.05)$ and deconvolved them. We then multiplied the time-series by a condition versus rest and convolved the time-series with the canonical hemodynamic response function in SPM. This procedure generated one interaction term per condition (i.e., GS $\pm 60 \%$, GS $\pm 40 \%$, GS $\pm 20 \%$, and $\mathrm{CS}_{\text {unpaired }}$ ), which were entered into a separate model. The model contained three regressors: the VTA time-series by "stimuli versus rest" interaction, "stimuli versus rest," and the unmodulated VTA time-series. The primary objective of this analysis was to investigate group differences in mesocorticolimbic connectivity (i.e., correlation) modulated by GS versus rest, the contrast in which GAD patients showed a significant increase in VTA BOLD activation relative to controls. To this end, we entered individual PPI $\beta$ images of the "GS versus rest" contrast into a random-effect second level model containing subject, group, and condition. The secondary objective was to examine effects of conditioned fear on the mesocorticolimbic circuit in both groups. To address this, we created a second PPI using "CS versus rest" as a psychological regressor and then examined mean effects of group in a randomeffect second level model. We corrected the results using a cluster extent method (AFNI's 3dClustSim; 10,000 Monte Carlo simulations) with an $\alpha$ of 0.005 for each ROI. Bilateral ROI masks were derived from the Automated Anatomical Labeling atlas. These include a broad medial prefrontal area (i.e., the medial frontal gyrus, the ventromedial PFC, and the ACC), the hippocampus, the ventral striatum, and the thalamus.
Table 1. Demographics and clinical characteristics across patients and controls

\begin{tabular}{|c|c|c|c|c|c|}
\hline \multirow[b]{2}{*}{ Variable } & \multicolumn{2}{|c|}{$\operatorname{GAD}(n=32)$} & \multicolumn{2}{|c|}{$\begin{array}{l}\text { Healthy control } \\
(n=25)\end{array}$} & \multirow[b]{2}{*}{ Significance ( $p$} \\
\hline & Mean & SD & Mean & SD & \\
\hline Age & 22.3 & 5.14 & 21.3 & 4.56 & $>0.5$ \\
\hline STAL-Trait ${ }^{a}$ & 55.1 & 10.08 & 37.5 & 6.52 & $<0.001$ \\
\hline $\mathrm{BDI}^{a}$ & 22.3 & 12.66 & 4.8 & 3.54 & $<0.001$ \\
\hline
\end{tabular}

${ }^{a}$ Data from Greenberg et al. (2013a).

\section{Results}

We first tested for generalization effects within the midbrain neural reactivity in individuals with GAD versus healthy controls (Table 1). After modeling effects of conditions using a general linear model in each individual, we investigated group differences in BOLD reactivity during generalization of conditioned fear. Individuals with GAD showed significantly greater midbrain VTA activation in response to GS compared with healthy controls at a small volume-corrected FWE $p<0.004(z=3.65$, MNI, 2, $-18,-14$; Fig. 2). Post hoc analyses on extracted BOLD estimates revealed a differential generalization gradient across groups (group $\times$ stimuli interaction, $F_{(2,178)}=3.31, p=0.04$, 


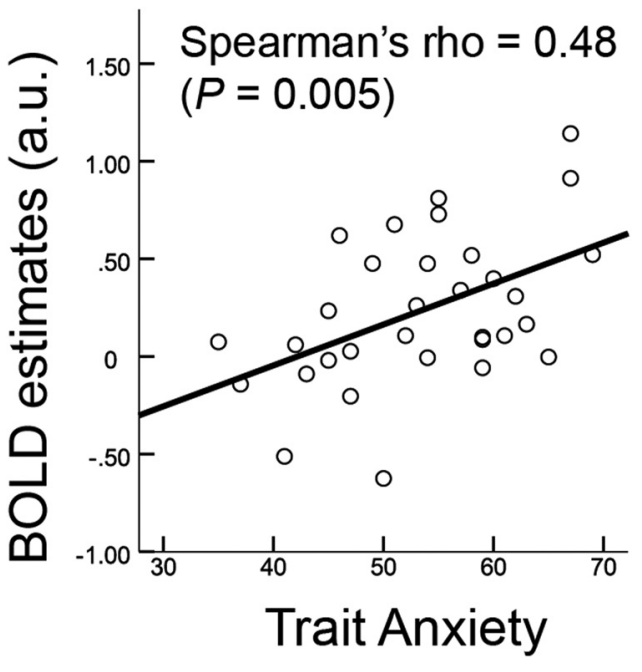

Figure 3. Correlation between VTA BOLD reactivity to GS (60\% different) and trait anxiety (STAI) in individuals with GAD. The effect was significant at an $\alpha$ level of 0.05 after Bonferroni adjustment for multiple conditions $(p<0.0125)$. Correlation was only significant in GS $\pm 60 \%$, but not other GS or CS $(p>0.14)$.

repeated-measures ANOVA): activation of healthy controls' VTA linearly tracked cue similarities to CS ( $\beta=0.57, p=0.01$, a post hoc linear trend analysis), but not in patients $(p>0.6)$, which apparently resulted from a heightened reactivity to GS $(p=0.00005)$, but not CS $(p>0.479)$. We further examined whether individual variability of the VTA hyper-reactivity in patients was correlated with self-reported anxiety and depression scales. Trait anxiety in Spielberger State-Trait Anxiety Inventory (STAI) (Spielberger, 2010) positively correlated with VTA reactivity to GS $\pm 60 \%$ in patients (Spearman's $r=0.48 ; p=0.005$ ) (Fig. 3). A positive correlation was also observed with the Beck Depression Inventory (BDI) (Beck et al., 1961) $(r=0.39 ; p=$ 0.027), which did not reach significance at Bonferroni-corrected $p$ of 0.0125 (i.e., by number of conditions). Partial correlations controlling for either STAI or BDI were marginally significant for STAI (Spearman's partial $r=0.31 ; p=0.08$ ), but not for BDI $(r=0.12, p=0.50)$. We found no significant correlations in other conditions $(p>0.28)$. These results suggest that anxiety is associated with elevated and indiscriminate VTA reactivity to GS.

The results of the hyper-reactive VTA in the GAD group raised the question of whether VTA activity would correlate with activity of the mesocorticolimbic circuit. To answer this question, we measured functional connectivity modulated by CS or GS using PPI analysis. We used a functionally defined VTA mask based on the group difference as our seed region, and anatomical masks for a priori ROIs, including a medial prefrontal cortical area (i.e., the medial frontal gyrus, the ventromedial PFC, and the ACC), the hippocampus, the ventral striatum, and the thalamus, given the well-established mesocorticolimbic circuit (Haber and Knutson, 2010). For a psychophysiological modulator, we used either "CS-Rest" or "GS-Rest." In both patient and controls alike, "CS-Rest" significantly increased VTA connectivity with prefrontal areas (i.e., mPFC/ACC and vmPFC), the hippocampus, and the thalamus (ROI-corrected $p<0.005$; Fig. 2; Table 2); no group differences were found in these ROIs. On the other hand, we observed a significant group difference in the VTA-accumbens connectivity, where individuals with GAD showed a significant increase in connectivity, but healthy controls did not (Fig. 2). No significant decreases were observed in
Table 2. VTA connectivity modulated by psychological regressors

\begin{tabular}{|c|c|c|c|c|c|c|}
\hline \multirow[b]{2}{*}{ Name } & \multirow{2}{*}{$\begin{array}{l}\text { Cluster } \\
\text { size }^{a}\end{array}$} & \multicolumn{2}{|l|}{ Peak } & \multicolumn{3}{|l|}{ MNI } \\
\hline & & $z$ & $p$ & $x$ & $y$ & $z$ \\
\hline \multicolumn{7}{|l|}{ Modulator: GS } \\
\hline \multicolumn{7}{|c|}{ Contrast: GAD > healthy controls } \\
\hline ACC & 61 & 3.77 & $7 \mathrm{E}-5$ & 2 & 34 & 26 \\
\hline Ventral striatum & 36 & 3.46 & $3 E-4$ & -8 & 8 & -6 \\
\hline Thalamus & 84 & 4.48 & $3 E-6$ & 8 & -8 & 18 \\
\hline Accumbens & 13 & 3.27 & 3.27 & -4 & 0 & -4 \\
\hline \multicolumn{7}{|c|}{ Contrast: healthy controls > GAD } \\
\hline Hippocampus & 34 & 4.78 & $9 \mathrm{E}-6$ & 30 & -36 & -6 \\
\hline \multicolumn{7}{|l|}{ Modulator: CS } \\
\hline \multicolumn{7}{|c|}{ Contrast: GAD > healthy controls } \\
\hline Accumbens & 63 & 3.46 & $3 E-4$ & -8 & 10 & -8 \\
\hline \multicolumn{7}{|c|}{ Contrast: mean positive effects } \\
\hline Ventromedial PFC & 131 & 4.35 & $6 \mathrm{E}-6$ & 2 & 40 & -16 \\
\hline Medial PFC & 290 & 4.15 & $1 \mathrm{E}-5$ & -4 & 56 & 8 \\
\hline ACC & - & 4.21 & $5 E-5$ & 2 & 44 & 6 \\
\hline Hippocampus & 33 & 3.81 & $6 \mathrm{E}-5$ & 22 & -14 & -20 \\
\hline Thalamus & 137 & 3.25 & $5 E-4$ & 4 & -20 & 6 \\
\hline
\end{tabular}

${ }^{a}$ Voxelwise $p<0.005$; all results at corrected $p<0.005$ in each ROI.

either group. These results suggest that activation of mesocorticolimbic circuit may be linked to threat encoding.

Given the VTA hyper-reactivity to GS in individuals with GAD, we expected that the "GS-Rest" contrast would elicit group differences in connectivity of this circuit. Indeed, we found significant increases in VTA connectivity with the ACC (rostral and subgenual), the accumbens, and the thalamus in GAD at ROIcorrected $p<0.005$, but not in healthy controls. On the other hand, the "GS-Rest" significantly increased VTA-hippocampus connectivity only in healthy controls, but not in GAD (Fig. 2; Table 2). In brief, individuals with GAD displayed a pattern of heightened VTA-mesocorticolimbic coupling and attenuated VTA-hippocampal coupling in GS, distinct from healthy controls.

Regarding our previous reports on vmPFC dysfunction in individuals with GAD (Greenberg et al., 2013a; Cha et al., 2014), we examined the relationship between the fear generalization gradient in the vmPFC and the VTA. The vmPFC fear generalization gradient is the slope of the linear fit on the fear generalization reactivity gradient (as a function of cue similarity to CS); this measure did not show a correlation with the VTA fear generalization gradient in either the patient group or in healthy controls ( $p>0.52$; nonparametric correlation). Furthermore, we did not find significant correlations with the vmPFC generalization and our PPI measures $(p>0.25)$.

\section{Discussion}

Here, we investigated the role of neuromodulatory midbrain and the broad corticolimbic system in threat-safety discrimination and whether abnormalities of this system are implicated in clinical anxiety. In healthy controls, the magnitude of activation in the VTA proportionally tracks the similarity of stimuli to CS, and mesocorticolimbic connectivity increases in response to CS. In individuals with GAD, however, the VTA is hyper-reactive to stimuli that resemble CS (i.e., GS) and mesocorticolimbic connectivity is significantly altered: increased in the ventral PFC and decreased in the hippocampus. These results suggest: (1) VTA activation and mesocortical connectivity are critical in threat processing; and (2) an abnormal mesocorticolimbic aversion system is implicated in the overgeneralization of conditioned fear in GAD.

Healthy controls and individuals with GAD alike showed VTA BOLD activation to the CS. This is in line with previous reports of 
VTA activation during perception or anticipation of aversive stimuli (Fairhurst et al., 2007; Matsumoto and Hikosaka, 2009), as well as fear learning (Lammel et al., 2012; Brooks and Berns, 2013). Our results complement and expand on these findings by demonstrating that the normal VTA activates proportionally to the perceptual similarity of the CS. Moreover, VTA connectivity with prefrontal regions increases in response to conditioned fear. One possible explanation is that this increase in mesocortical connectivity represents the activation of VTA dopaminergic projections to the prefrontal system during threat processing. This idea is consistent with a recent animal model of dopaminergic aversion signaling, in which glutamatergic inputs from the lateral habenula excite dopaminergic neurons in the medial VTA, which in turn project to the $\mathrm{mPFC}$, completing the mesocortical aversion circuit (Lammel et al., 2012). It should be noted, however, that the present $\mathrm{fMRI}$ results do not provide direct evidence of the involvement of dopamine or the directionality of connectivity.

Individuals with GAD showed greater VTA reactivity to all GS compared with healthy controls. This led to a significant group difference in the VTA fear generalization gradient: a linear increase in VTA reactivity with increase in perceptual similarity to the CS (threat) in healthy controls, but indiscriminately enhanced VTA activation, to all stimuli regardless of perceptual similarity to CS (threat), in individuals with GAD. This effect is well in line with the model of overgeneralization of conditioned fear in pathological anxiety (Jovanovic and Ressler, 2010; Britton et al., 2011; Kheirbek et al., 2012; Greenberg et al., 2013a). Furthermore, variability of the patient-specific VTA hyper-reactivity to the GS least similar to CS was correlated with individual differences in trait anxiety. In animal models, excessive VTA dopaminergic activity is implicated in anxiety-like behaviors (Coque et al., 2011), and elevated VTA dopaminergic activity has been linked to vulnerability to social defeat in mouse models (Krishnan et al., 2007). Thus, our results seem to correspond to previous research in animal models providing a key link between abnormal VTA activity and anxiety. Future research may investigate whether the abnormal VTA BOLD reactivity reported here is indeed correlated with an increase in dopamine release or receptor activity.

We also found abnormal mesocorticolimbic connectivity in GAD. First, individuals with GAD showed heightened mesocorticolimbic coupling elicited by GS compared with healthy controls. Although speculative, one of the many potential neurobiological underpinnings of this maladaptive mesocorticolimbic coupling in clinical anxiety may be a disturbance of the "aversive" dopaminergic system because of excessive or prolonged stress (Coplan et al., 1996; Arborelius et al., 1999). In mouse models, chronic stress induces excessive glucocorticoid release in dopaminoreceptive neurons in the PFC (Barik et al., 2013). Chronic stress also leads to DNA hypermethylation of the tyrosine hydroxylase gene, a key regulator of dopamine synthesis, and this epigenetic influence is observed in mesocortical dopaminergic neurons (Niwa et al., 2013). Partially in line with this, recent human dopamine receptor imaging results suggest that acute stressors induce dopamine release in the mPFC and physiological arousal in healthy individuals (Nagano-Saito et al., 2013). Based on this literature, although speculative, the heightened mesocorticolimbic connectivity during fear generalization may indicate an aberrant dopaminergic mesocorticolimbic circuit in clinical anxiety.

Second, VTA-hippocampal connectivity elicited by GS was significantly attenuated in individuals with GAD compared with healthy controls. The hippocampus interacts with the VTA, forming a VTA-hippocampal loop that is crucial in motivational learning and memory (Lisman and Grace, 2005; Lodge and Grace, 2006; Shohamy and Wagner, 2008). Our results suggest that the attenuation of the VTA-hippocampal loop is associated with impaired threat-safety discrimination in clinical anxiety. This finding is in line with a recent animal model implicating impaired hippocampal pattern separation, perhaps via restrained neurogenesis under stress, to fear generalization and anxiety-related behaviors (Kheirbek et al., 2012). Together, our connectivity results support the idea that the abnormal mesocorticolimbic system contributes to overgeneralization of conditioned fear in GAD.

The present study advances the current understanding of the neural underpinnings of fear generalization. Several neuroimaging studies report neural correlates of fear generalization in humans, including the cingulate cortex, insula, striatum, and other limbic structures (Dunsmoor et al., 2011; Greenberg et al., 2013b; Lissek et al., 2013b). Studies of clinical anxiety document behavioral and/or neural evidence of fear generalization in anxiety disorders, such as panic disorder (Lissek et al., 2010) and GAD (Greenberg et al., 2013a; Lissek et al., 2013a). In particular, we have previously reported maladaptive vmPFC threat processing in GAD; that is, an indiscriminate vmPFC response to fear generalization stimuli (Greenberg et al., 2013a) showed correlations between circuit-wide structural and functional abnormalities (Cha et al., 2014). In the present study, we did not observe a direct relationship between vmPFC dysfunction and abnormal VTA reactivity or connectivity. However, given the extensive literature on the essential role of the two systems (perhaps mediated by the dorsolateral PFC) in adaptive behavior (Schoenbaum et al., 2009; Takahashi et al., 2009, 2011; Ballard et al., 2011; D'Ardenne et al., 2012), the coupling between these two structures may be important in the fear generalization and the pathophysiology of anxiety.

In conclusion, our findings in the present study provide novel evidence linking the abnormal mesocorticolimbic system to the overgeneralization of conditioned threat in GAD. Further investigation of the neurochemical substrates for these BOLD-based measures may contribute to the development of new treatment strategies targeting the dopaminergic mesocorticolimbic aversion circuit in anxiety disorders.

\section{References}

Anstrom KK, Miczek KA, Budygin EA (2009) Increased phasic dopamine signaling in the mesolimbic pathway during social defeat in rats. Neuroscience 161:3-12. CrossRef Medline

Arborelius L, Owens MJ, Plotsky PM, Nemeroff CB (1999) The role of corticotropin-releasing factor in depression and anxiety disorders. J Endocrinol 160:1-12. CrossRef Medline

Ballard IC, Murty VP, Carter RM, MacInnes JJ, Huettel SA, Adcock RA (2011) Dorsolateral prefrontal cortex drives mesolimbic dopaminergic regions to initiate motivated behavior. J Neurosci 31:10340-10346. CrossRef Medline

Barik J, Marti F, Morel C, Fernandez SP, Lanteri C, Godeheu G, Tassin JP, Mombereau C, Faure P, Tronche F (2013) Chronic stress triggers social aversion via glucocorticoid receptor in dopaminoceptive neurons. Science 339:332-335. CrossRef Medline

Beck AT, Ward C, Mendelson M, Mock J, Erbaugh J (1961) Beck Depression Inventory (BDI). Arch Gen Psychiatry 4:561-571. CrossRef Medline

Berridge KC, Robinson TE (1998) What is the role of dopamine in reward: hedonic impact, reward learning, or incentive salience? Brain Res Brain Res Rev 28:309-369. CrossRef Medline

Britton JC, Lissek S, Grillon C, Norcross MA, Pine DS (2011) Development of anxiety: the role of threat appraisal and fear learning. Depress Anxiety 28:5-17. CrossRef Medline

Bromberg-Martin ES, Matsumoto M, Hikosaka O (2010) Dopamine in mo- 
tivational control: rewarding, aversive, and alerting. Neuron 68:815-834. CrossRef Medline

Brooks AM, Berns GS (2013) Aversive stimuli and loss in the mesocorticolimbic dopamine system. Trends Cogn Sci 17:281-286. CrossRef Medline

Cabib S, Puglisi-Allegra S (1996) Stress, depression and the mesolimbic dopamine system. Psychopharmacology 128:331-342. CrossRef Medline

Cha J, Greenberg T, Carlson JM, Dedora D, Hajcak G, Mujica-Parodi LR (2014) Circuit-wide structural and functional factors of ventromedial prefrontal fear response and contribution to anxiety disorder. J Neurosci 34:4032-4053. CrossRef Medline

Cohen JY, Haesler S, Vong L, Lowell BB, Uchida N (2012) Neuron-typespecific signals for reward and punishment in the ventral tegmental area. Nature 482:85-88. CrossRef Medline

Coplan JD, Andrews MW, Rosenblum LA, Owens MJ, Friedman S, Gorman JM, Nemeroff CB (1996) Persistent elevations of cerebrospinal fluid concentrations of corticotropin-releasing factor in adult nonhuman primates exposed to early-life stressors: implications for the pathophysiology of mood and anxiety disorders. Proc Natl Acad Sci U S A 93:1619-1623. CrossRef Medline

Coque L, Mukherjee S, Cao JL, Spencer S, Marvin M, Falcon E, Sidor MM, Birnbaum SG, Graham A, Neve RL, Gordon E, Ozburn AR, Goldberg MS, Han MH, Cooper DC, McClung CA (2011) Specific role of VTA dopamine neuronal firing rates and morphology in the reversal of anxietyrelated, but not depression-related behavior in the ClockDelta19 mouse model of mania. Neuropsychopharmacology 36:1478-1488. CrossRef Medline

D’Ardenne K, Eshel N, Luka J, Lenartowicz A, Nystrom LE, Cohen JD (2012) Role of prefrontal cortex and the midbrain dopamine system in working memory updating. Proc Natl Acad Sci U S A 109:19900-19909. CrossRef Medline

Deutch AY, Roth RH (1990) The determinants of stress-induced activation of the prefrontal cortical dopamine system. Prog Brain Res 85:367-402; discussion 402-403. Medline

Dunsmoor JE, Prince SE, Murty VP, Kragel PA, LaBar KS (2011) Neurobehavioral mechanisms of human fear generalization. Neuroimage 55: 1878-1888. CrossRef Medline

Fairhurst M, Wiech K, Dunckley P, Tracey I (2007) Anticipatory brainstem activity predicts neural processing of pain in humans. Pain 128:101-110. CrossRef Medline

Greenberg T, Carlson JM, Cha J, Hajcak G, Mujica-Parodi LR (2013a) Ventromedial prefrontal cortex reactivity is altered in generalized anxiety disorder during fear generalization. Depress Anxiety 30:242-250. CrossRef Medline

Greenberg T, Carlson JM, Cha J, Hajcak G, Mujica-Parodi LR (2013b) Neural reactivity tracks fear generalization gradients. Biol Psychol 92:2-8. CrossRef Medline

Haber SN, Knutson B (2010) The reward circuit: linking primate anatomy and human imaging. Neuropsychopharmacology 35:4-26. CrossRef Medline

Jovanovic T, Ressler KJ (2010) How the neurocircuitry and genetics of fear inhibition may inform our understanding of PTSD. Am J Psychiatry 167: 648-662. CrossRef Medline

Kheirbek MA, Klemenhagen KC, Sahay A, Hen R (2012) Neurogenesis and generalization: a new approach to stratify and treat anxiety disorders. Nat Neurosci 15:1613-1620. CrossRef Medline

Krishnan V, Han MH, Graham DL, Berton O, Renthal W, Russo SJ, Laplant Q, Graham A, Lutter M, Lagace DC, Ghose S, Reister R, Tannous P, Green TA, Neve RL, Chakravarty S, Kumar A, Eisch AJ, Self DW, Lee FS, et al. (2007) Molecular adaptations underlying susceptibility and resistance to social defeat in brain reward regions. Cell 131:391-404. CrossRef Medline

Lammel S, Lim BK, Ran C, Huang KW, Betley MJ, Tye KM, Deisseroth K, Malenka RC (2012) Input-specific control of reward and aversion in the ventral tegmental area. Nature 491:212-217. CrossRef Medline

Lisman JE, Grace AA (2005) The hippocampal-VTA loop: controlling the entry of information into long-term memory. Neuron 46:703-713. CrossRef Medline

Lissek S, Rabin S, Heller RE, Lukenbaugh D, Geraci M, Pine DS, Grillon C (2010) Overgeneralization of conditioned fear as a pathogenic marker of panic disorder. Am J Psychiatry 167:47-55. CrossRef Medline

Lissek S, Kaczkurkin AN, Rabin S, Geraci M, Pine DS, Grillon C (2013a) Generalized anxiety disorder is associated with overgeneralization of classically conditioned fear. Biol Psychiatry. Advance online publication. Retrieved Aug. 31, 2013. doi: 10.1016/j.biopsych.2013.07.025. CrossRef Medline

Lissek S, Bradford DE, Alvarez RP, Burton P, Espensen-Sturges T, Reynolds RC, Grillon C (2013b) Neural substrates of classically conditioned feargeneralization in humans: a parametric fMRI study. Soc Cogn Affect Neurosci. Advance online publication. Retrieved July 16, 2013. doi: 10.1093/scan/nst096. CrossRef Medline

Lodge DJ, Grace AA (2006) The hippocampus modulates dopamine neuron responsivity by regulating the intensity of phasic neuron activation. Neuropsychopharmacology 31:1356-1361. CrossRef Medline

Matsumoto M, Hikosaka O (2009) Two types of dopamine neuron distinctly convey positive and negative motivational signals. Nature 459 : 837-841. CrossRef Medline

Nagano-Saito A, Dagher A, Booij L, Gravel P, Welfeld K, Casey KF, Leyton M, Benkelfat C (2013) Stress-induced dopamine release in human medial prefrontal cortex-18F-fallypride/PET study in healthy volunteers. Synapse 67:821-830. CrossRef Medline

Naidich TP, Duvernoy HM, Delman BN, Sorensen AG, Kollias SS, Haacke EM (2009) Duvernoy's atlas of the human brain stem and cerebellum, Ed 12. New York: Springer.

Niwa M, Jaaro-Peled H, Tankou S, Seshadri S, Hikida T, Matsumoto Y, Cascella NG, Kano S, Ozaki N, Nabeshima T, Sawa A (2013) Adolescent stress-induced epigenetic control of dopaminergic neurons via glucocorticoids. Science 339:335-339. CrossRef Medline

Schoenbaum G, Roesch MR, Stalnaker TA, Takahashi YK (2009) A new perspective on the role of the orbitofrontal cortex in adaptive behaviour. Nat Rev Neurosci 10:885-892. CrossRef Medline

Schultz W (2002) Getting formal with dopamine and reward. Neuron 36: 241-263. CrossRef Medline

Shohamy D, Wagner AD (2008) Integrating memories in the human brain: hippocampal-midbrain encoding of overlapping events. Neuron 60:378 389. CrossRef Medline

Spielberger CD (2010) State-trait anxiety inventory. In: Corsini encyclopedia of psychology. Hoboken, NJ: John Wiley \& Sons.

Stamatakis AM, Stuber GD (2012) Activation of lateral habenula inputs to the ventral midbrain promotes behavioral avoidance. Nat Neurosci 15: 1105-1107. CrossRef Medline

Takahashi YK, Roesch MR, Stalnaker TA, Haney RZ, Calu DJ, Taylor AR, Burke KA, Schoenbaum G (2009) The orbitofrontal cortex and ventral tegmental area are necessary for learning from unexpected outcomes. Neuron 62:269-280. CrossRef Medline

Takahashi YK, Roesch MR, Wilson RC, Toreson K, O’Donnell P, Niv Y, Schoenbaum G (2011) Expectancy-related changes in firing of dopamine neurons depend on orbitofrontal cortex. Nat Neurosci 14:15901597. CrossRef Medline

Thierry AM, Tassin JP, Blanc G, Glowinski J (1976) Selective activation of mesocortical DA system by stress. Nature 263:242-244. CrossRef Medline

Willner P (1983) Dopamine and depression: a review of recent evidence: I. Empirical studies. Brain Res 287:211-224. Medline

Zacharko RM, Anisman H (1991) Stressor-induced anhedonia in the mesocorticolimbic system. Neurosci Biobehav Rev 15:391-405. CrossRef Medline

Zweifel LS, Fadok JP, Argilli E, Garelick MG, Jones GL, Dickerson TM, Allen JM, Mizumori SJ, Bonci A, Palmiter RD (2011) Activation of dopamine neurons is critical for aversive conditioning and prevention of generalized anxiety. Nat Neurosci 14:620-626. CrossRef Medline 